\title{
Enhancing the Operability of Photoexcitation-Controlled Aggregation-Induced Emissive Molecules in the Organic Phase
}

Taoyu Weng, ${ }^{\dagger, \nabla}$ Qi Zou, ${ }^{*,+, \nabla}$ Man Zhang, ${ }^{\dagger}$ Bin Wu, ${ }^{\dagger}$ Glib V. Baryshnikov,, Shen Shen, ${ }^{\dagger}$ Xuanying Chen,,$*$ Hans

$$
\text { Ågren, }{ }^{\perp, \S} \text { Xiaoyong Jia, }{ }^{*,} \text { Liangliang Zhu }{ }^{*,+}
$$

†State Key Laboratory of Molecular Engineering of Polymers, Department of Macromolecular Science, Fudan University, Shanghai 200438, China.

Key Laboratory for Advanced Materials and Feringa Nobel Prize Scientist Joint Research Center, Frontiers

Science Center for Materiobiology and Dynamic Chemistry, School of Chemistry and Molecular Engineering, East China University of Science and Technology, Shanghai 200237, China.

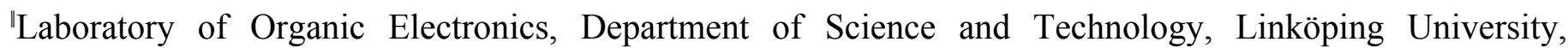
Norrköping, SE-60174 Sweden.

${ }^{\perp}$ Department of Physics and Astronomy, Uppsala University, Box 516, SE-751 20 Uppsala, Sweden

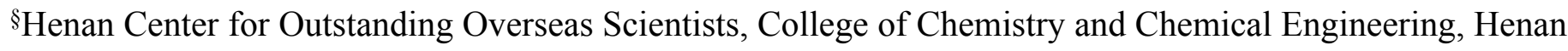
University, Kaifeng, Henan 475004, China.

$\nabla$ T. W. and Q. Z. contributed equally to this work.

*zhuliangliang@fudan.edu.cn (L. Z.); zouqi@ecust.edu.cn (Q. Z.); jiaxiaoyong@henu.edu.cn (X. J.) 


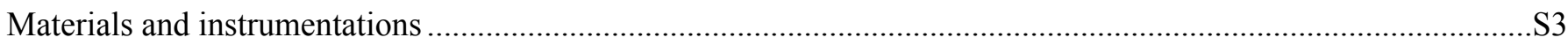

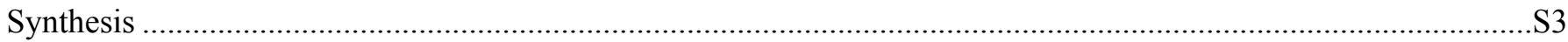

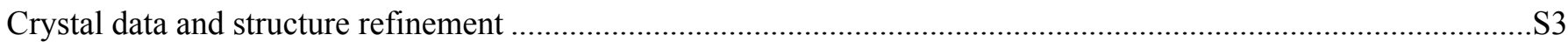

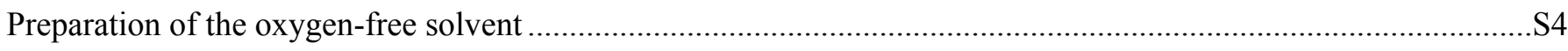

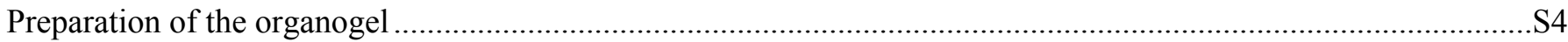

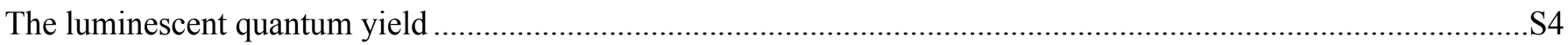

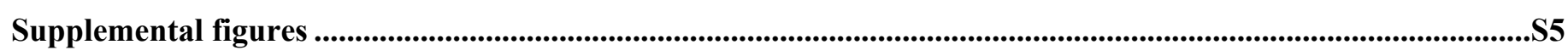

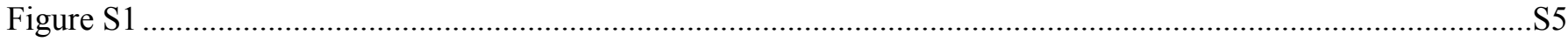

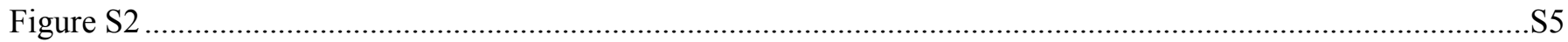

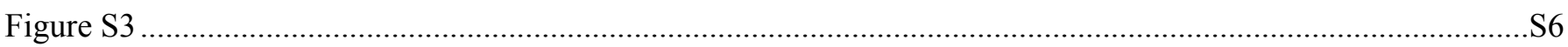

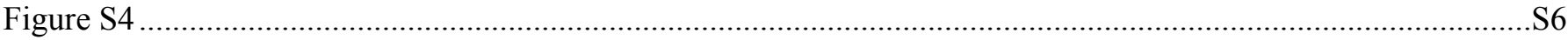

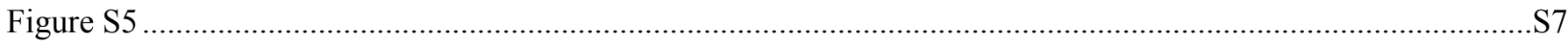

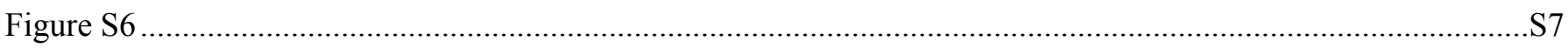

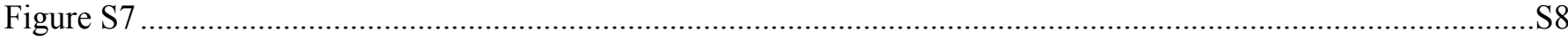

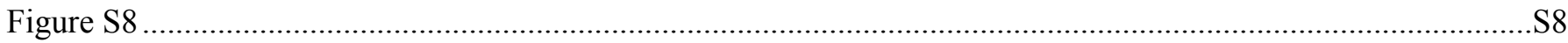

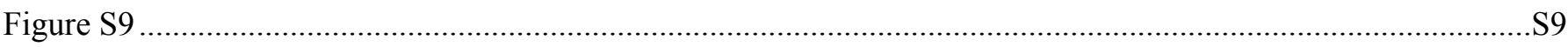

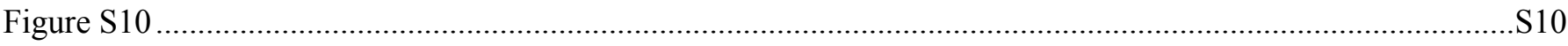

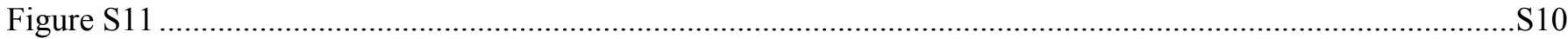

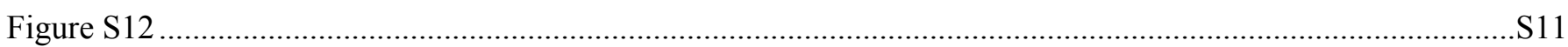

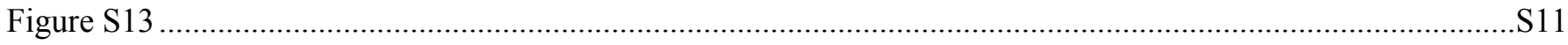




\section{General Information}

\section{Materials and instrumentations}

All materials and reagents were commercially available and used without additional purification. ${ }^{1} \mathrm{H}$ NMR and ${ }^{13} \mathrm{C}$ NMR spectra were recorded on Brucker AM-400 spectrometers with tetramethylsilane (TMS) as the internal standard. High-resolution mass spectrometry (HR-MS) were recorded on a Matrix Assisted Laser Desorption Ionization-Time of Flight (MALDI-TOF) Mass Spectrometer (5800).

UV-vis absorption spectra were recorded on a Shimadzu 1800 spectrophotometer, while the emission spectra and transient PL decay characteristics of the samples were recorded on an Edinburgh FLS1000. The fluorescence quantum yields of solutions and solid powders were measured on QM40 with an integrating sphere $(\varphi 150 \mathrm{~mm})$ from Photo Technology International, Inc. (PTI, Horiba Scientific). X-ray diffraction measurements were performed by a PANalytical X'Pert PRO. The electron spin paramagnetic resonace (ESR) spectrum was measured on JES-FA200 from JEOL Ltd.

Dynamic light scattering (DLS) experiments were measured with Nano-Zeta Potential Analyzer ZS-90. Transmission electron microscopy (TEM) images were obtained on a JEM-2100F microscope (JEOL, Japan).

\section{Synthesis}

The synthesis of compound 1 is exactly the same as the previous method. ${ }^{[\mathrm{S} 1]}$ So the ${ }^{1} \mathrm{H}$ NMR, ${ }^{13} \mathrm{C}$ NMR and HRMS(MALDI-TOF) are no longer provided.

\section{Crystal data and structure refinement}

Table S1. Crystal data and structure refinement for compound 1.

Empirical formula
Formula weight
Temperature
Wavelength
Crystal system, space group
Unit cell dimensions
Unit cell dimensions
Unit cell dimensions
Volume
Z, Calculated density

Absorption coefficient

$\mathrm{F}(000)$

Crystal size

Theta range for data collection

Limiting indices

Reflections collected / unique

Completeness to theta $=27.18$

Absorption correction

Max. and min. transmission

Refinement method

Data / restraints / parameters

Goodness-of-fit on $\mathrm{F}^{\wedge} 2$

Final R indices [I $>2 \operatorname{sigma}(\mathrm{I})]$

$\mathrm{R}$ indices (all data)

Largest diff. peak and hole
$\mathrm{C}_{42} \mathrm{H}_{30} \mathrm{~S}_{6}$

727.08

187(2) K

$0.71073 \AA$

Triclinic, $\mathrm{P}-1$

$a=9.6057(5) \AA \quad$ alpha $=68.404(2) \mathrm{deg}$.

$\mathrm{b}=10.2829(6) \AA \quad$ beta $=76.935(2) \mathrm{deg}$.

$\mathrm{c}=10.6577(6) \AA \quad$ gamma $=65.4940(10) \mathrm{deg}$.

$887.28(9) \AA \wedge 3$

$1,1.361 \mathrm{Mg} / \mathrm{m}^{\wedge} 3$

$0.416 \mathrm{~mm}^{\wedge}-1$

378

$0.43 \times 0.28 \times 0.10 \mathrm{~mm}$

2.06 to $27.18 \mathrm{deg}$.

$-12<=\mathrm{h}<=12,-13<=\mathrm{k}<=13,-13<=\mathrm{l}<=12$

$11123 / 3859[\mathrm{R}(\mathrm{int})=0.0355]$

$97.8 \%$

None

0.959 and 0.870

Full-matrix least-squares on $\mathrm{F}^{\wedge} 2$

3859 / 0 / 217

1.334

$\mathrm{R} 1=0.0376, \mathrm{wR} 2=0.1484$

$\mathrm{R} 1=0.0395, \mathrm{wR} 2=0.1531$

0.351 and -0.291 e. $\AA \wedge-3$ 
Table S2. Crystal data and structure refinement for compound 1'.

Empirical formula
Formula weight
Temperature
Wavelength
Crystal system, space group
Unit cell dimensions
Unit cell dimensions
Unit cell dimensions
Volume
Z, Calculated density

Absorption coefficient

$\mathrm{F}(000)$

Crystal size

Theta range for data collection

Limiting indices

Reflections collected / unique

Completeness to theta $=27.18$

Absorption correction

Max. and min. transmission

Refinement method

Data / restraints / parameters

Goodness-of-fit on $\mathrm{F}^{\wedge} 2$

Final $\mathrm{R}$ indices [I $>2 \operatorname{sigma}(\mathrm{I})]$

$\mathrm{R}$ indices (all data)

Largest diff. peak and hole
C42H30S6

727.02

244(2) K

$0.71073 \AA$

Triclinic, P-1

$\mathrm{a}=9.6028(9) \AA \quad$ alpha $=68.434(3) \mathrm{deg}$.

$\mathrm{b}=10.2778(9) \AA \quad$ beta $=76.996(3) \mathrm{deg}$.

$\mathrm{c}=10.6672(10) \AA \quad$ gamma $=65.489(2) \mathrm{deg}$.

887.59(9) $\AA^{\wedge} 3$

$1,1.360 \mathrm{Mg} / \mathrm{m}^{\wedge} 3$

$0.416 \mathrm{~mm}^{\wedge}-1$

378

$0.37 \times 0.15 \times 0.10 \mathrm{~mm}$

2.06 to $26.96 \mathrm{deg}$.

$-12<=\mathrm{h}<=12,-13<=\mathrm{k}<=13,-13<=\mathrm{l}<=13$

$10518 / 3788[\mathrm{R}(\mathrm{int})=0.0293]$

$98.3 \%$

None

0.959 and 0.928

Full-matrix least-squares on $\mathrm{F}^{\wedge} 2$

$3788 / 0 / 217$

1.375

$\mathrm{R} 1=0.0366, \mathrm{wR} 2=0.1464$

$\mathrm{R} 1=0.0383, \mathrm{wR} 2=0.1535$

0.341 and -0.340 e. $\AA^{\wedge}-3$

\section{Preparation of the oxygen-free solvent}

A Schlenk tube was pumped with argon three times before adding the required solvent. The bottle is placed in liquid nitrogen. The solidified solvent is pumped in the liquid nitrogen for five minutes before naturally cooling to room temperature. The above steps are repeated three times. After the last time, the bottle is filled with argon gas and the solution is sucked with a syringe for used.

\section{Preparation of the organogel}

Compound 1 was dispersed into a dichloromethane solution containing $90 \mathrm{wt} \%$ of PMMA to form a saturated solution, and the concentration of compound 1 is $10 \mu \mathrm{M}$. The bottle was covered and stood in the dark for 1 hour to form an immobile organic gel.

Table S3. The luminescent quantum yield of compound 1 before and after irradiation by UV in different solutions.

\begin{tabular}{|l|l|l|l|l|l|l|l|l|}
\hline & DCM & THF & TCM & EA & Diox & ACN & DMF & DMSO \\
\hline Emission Peak (nm) & 470 & 475 & 480 & 480 & 490 & 500 & 520 & 530 \\
\hline $\begin{array}{l}\text { QY } \\
\text { (Initial State) }\end{array}$ & $<0.1 \%$ & $<0.1 \%$ & $<0.1 \%$ & $<0.1 \%$ & $<0.1 \%$ & $<0.1 \%$ & $<0.1 \%$ & $<0.1 \%$ \\
\hline $\begin{array}{l}\text { QY } \\
\text { (After irradiation by UV) }\end{array}$ & $9.0 \%$ & $10.5 \%$ & $8.4 \%$ & $8.0 \%$ & $13.0 \%$ & $8.6 \%$ & $17.8 \%$ & $18.6 \%$ \\
\hline
\end{tabular}




\section{Supplemental figures}
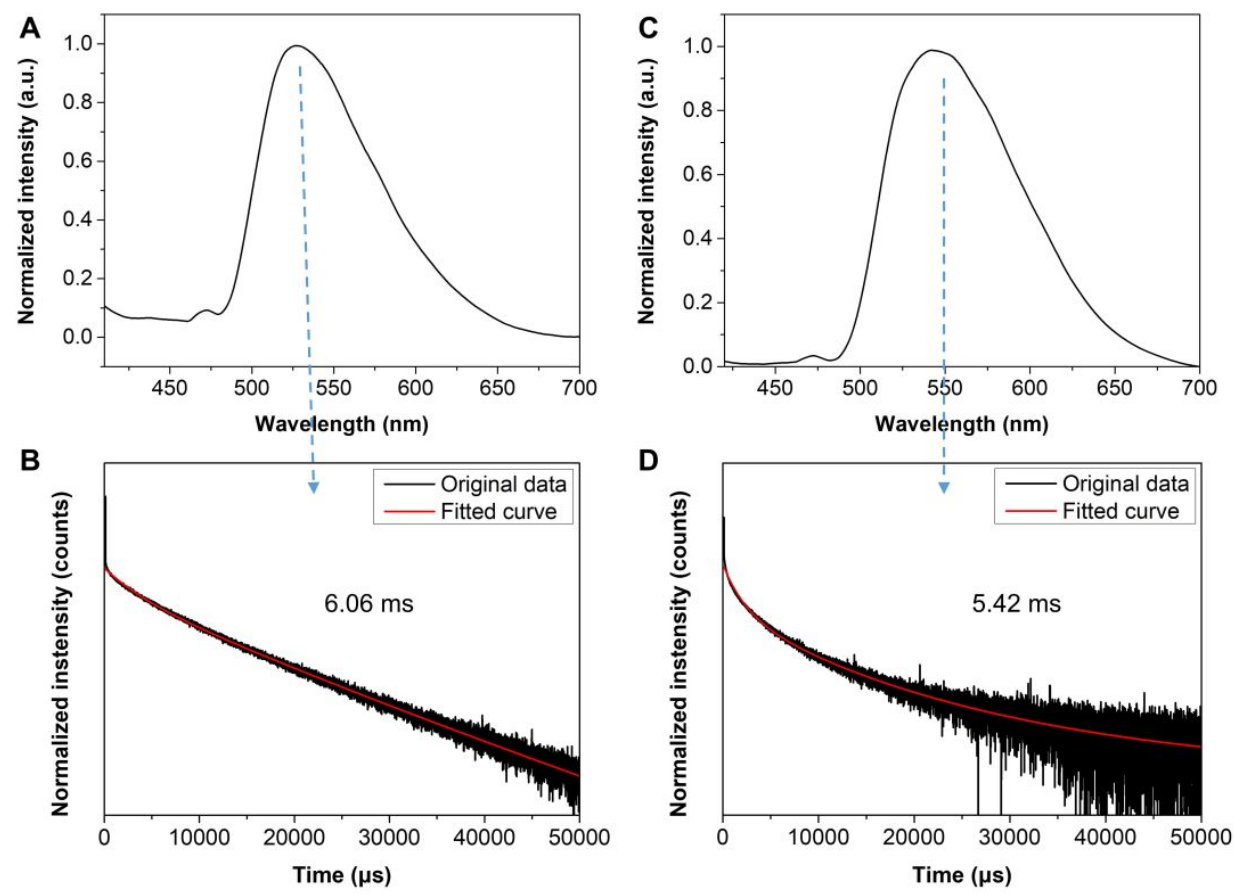

Figure S1. Photophysical properties of compound 1 at $77 \mathrm{~K}$. Emission spectra and corresponding photoluminescent lifetimes of compound 1 in DCM (A and C) and solid sample (C and D), respectively.
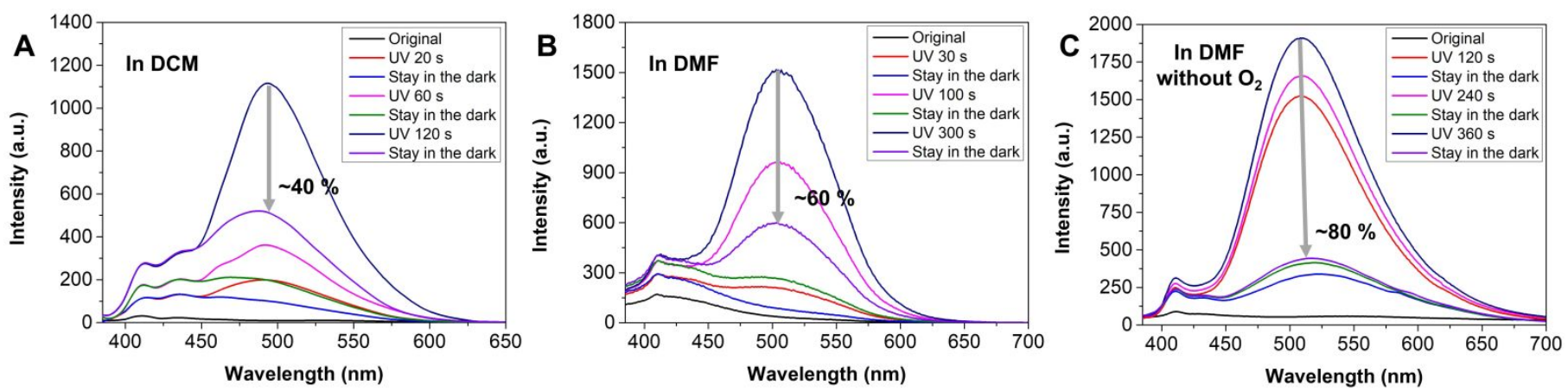

Figure S2. Self-recovery behavior of photo-irradiated compound $1(10 \mu \mathrm{M})$ in different organic solvents in dark. Emission changes of compound 1 in DCM (A), DMF (B) and DMF without $\mathrm{O}_{2}(\mathrm{C})$ after UV (365 nm, 4W) irradiation within different time frame, respectively, followed by standing in dark within the same period. The recovery ratios of the emission have been given in figures. 

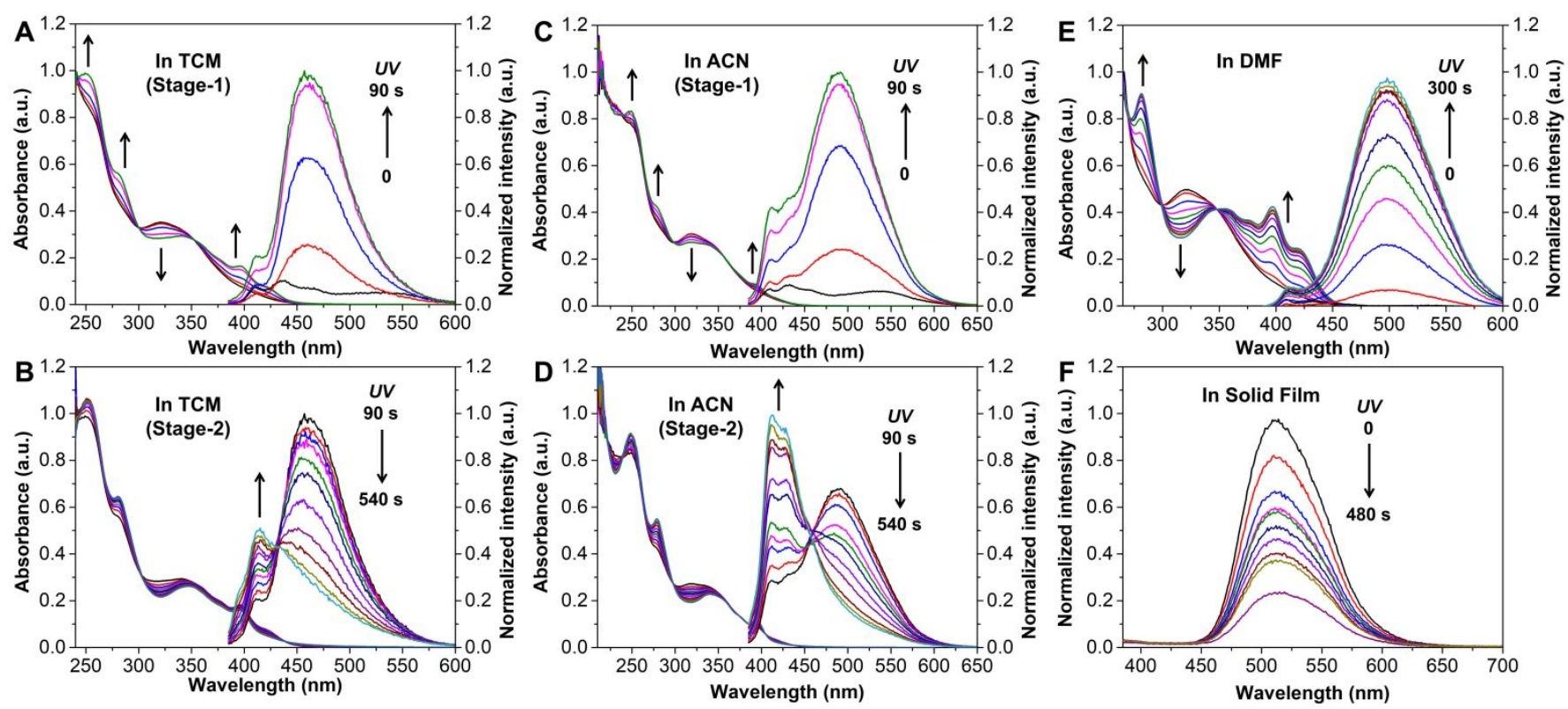

Figure S3. Photosensitivity of compound $1(10 \mu \mathrm{M})$ in different organic solvents upon irradiation with UV light (365 nm, $5 \mathrm{~W})$ within different time frame at $25^{\circ} \mathrm{C}$. Two-stage changes of absorption spectra and emission spectra of compound 1 under irradiation with UV light in TCM (A, B) and ACN (C, D). (E) The one-stage changes of absorption spectra and emission spectra of compound 1 under irradiation with UV light in DMF. (F) The emission changes of compound 1 in the film state under irradiation with UV light.

A
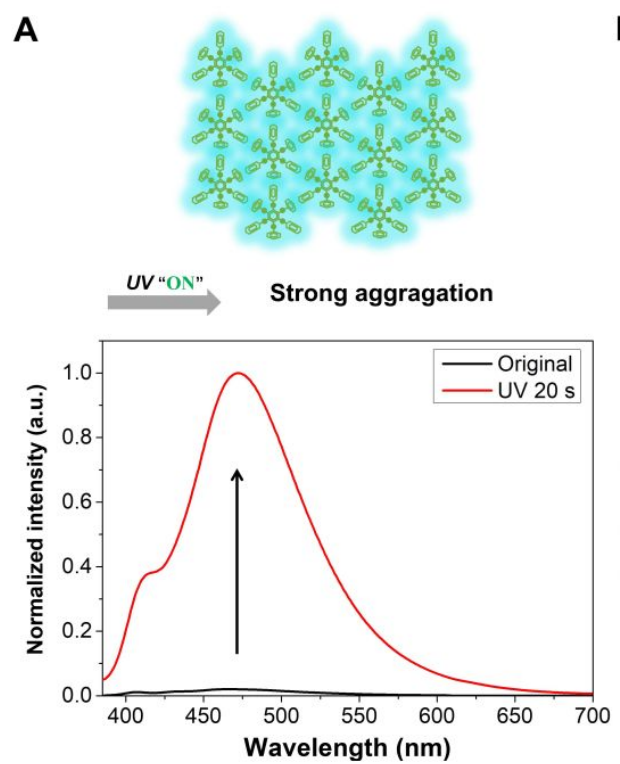

B

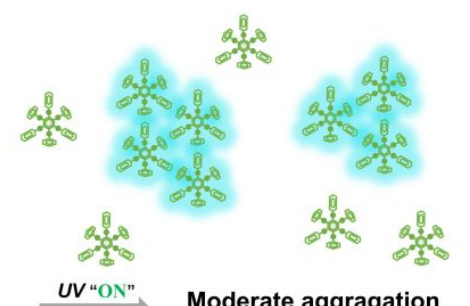

UV "ON" Moderate aggragation

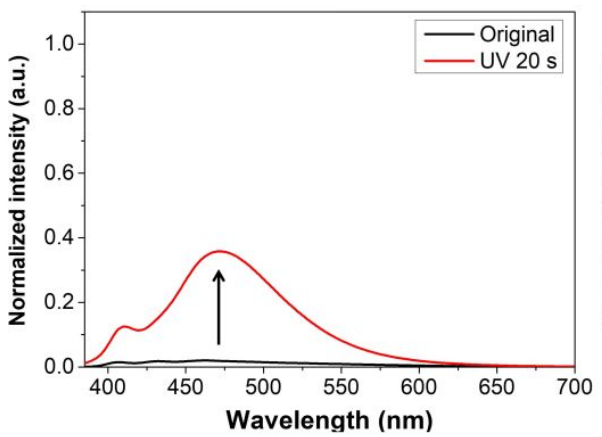

C
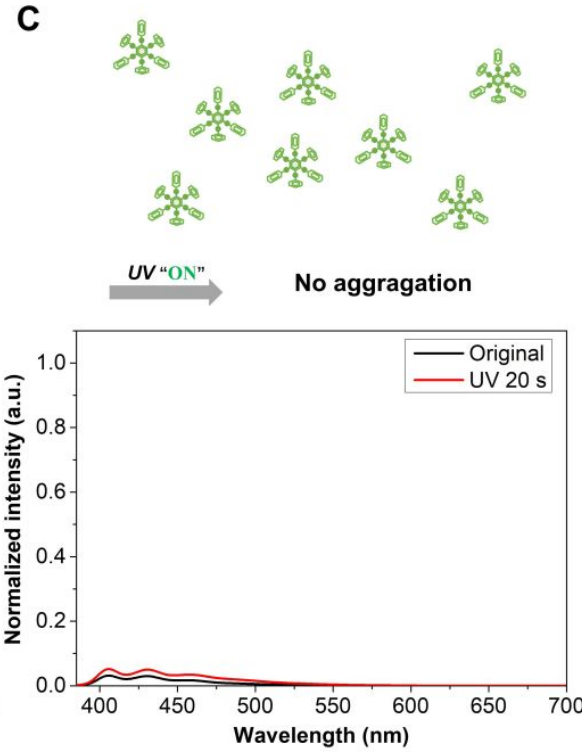

Figure S4. Molecular motion exploration. Emission enhancements of compound 1 in DCM before and after irradiation for $20 \mathrm{~s}$ with the concentration of compound 1 unit at $100 \mu \mathrm{M}(\mathrm{A}), 10 \mu \mathrm{M}(\mathrm{B})$, and $1 \mu \mathrm{M}(\mathrm{C})$. 


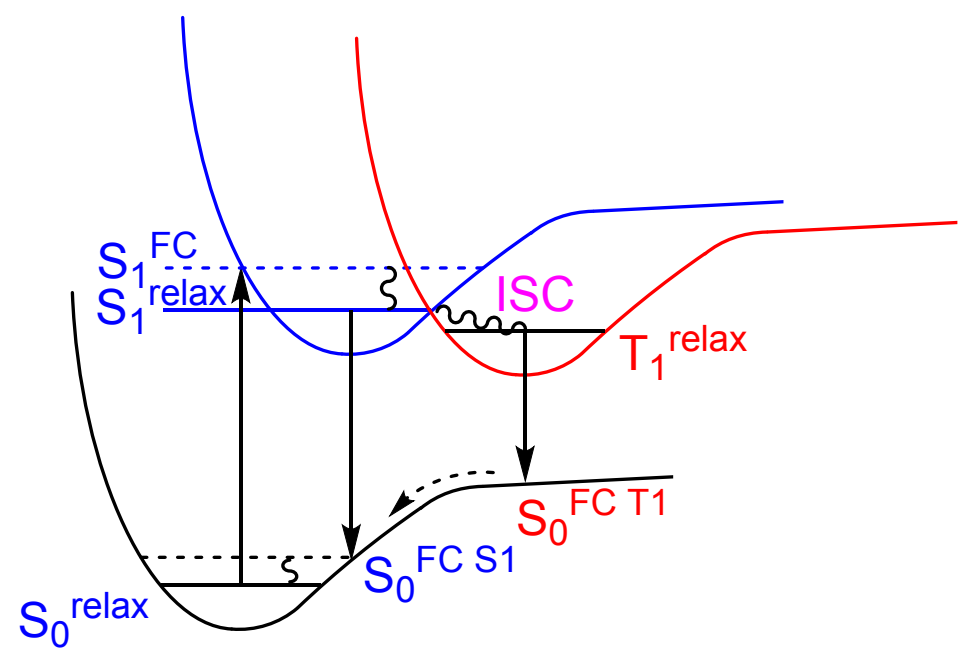

\begin{tabular}{|c|c|c|c|}
\hline Transition & $\lambda, \mathbf{n m}$ & $\mathbf{f}$ & Assignment \\
\hline $\mathrm{S}_{\mathbf{0}}{ }^{\text {relax }}-\mathrm{S}_{\mathbf{1}}{ }_{\mathrm{FC}}$ & 317 & 0.085 & HOMO-LUMO (95\%) \\
\hline$S_{1}{ }^{\text {relax }}-S_{0}{ }^{F C ~ S 1}$ & 463 & $2.6 \cdot 10^{-5}$ & HOMO-LUMO (97 \%) \\
\hline $\mathrm{T}_{1}{ }^{\text {relax }}-\mathrm{S}_{0} \mathrm{FC} \mathrm{T1}$ & 500 & $4.3 \cdot 10^{-7}$ & HOMO-LUMO (93\%) \\
\hline
\end{tabular}

Figure S5. The main photophysical processes occurred for compound 1 under photoexcitation. Combined data on vertical absorption and emission properties for compound 1 calculated by cam-B3LYP/6-31G(d,p) method with accounting of DCM solvent effect through PCM model.

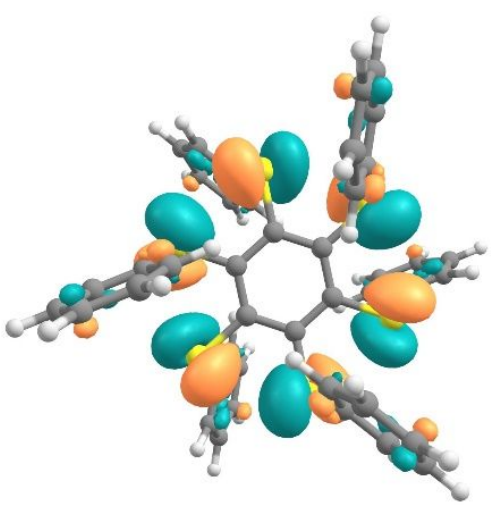

HOMO

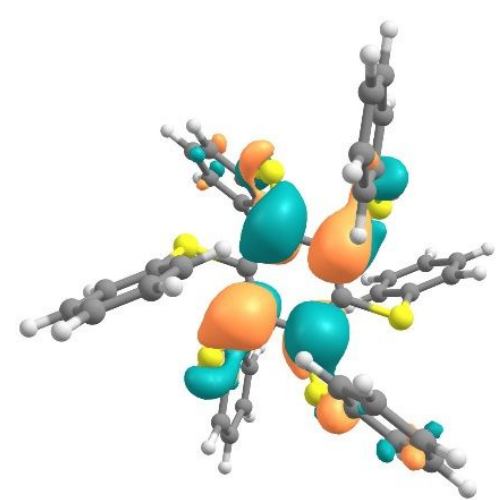

LUMO

Figure S6. The shape of HOMO and LUMO orbitals responsible for $\mathrm{S}_{0}{ }^{\text {relax }}-\mathrm{S}_{1}{ }^{\mathrm{FC}}$ adsorption and $\mathrm{S}_{1}{ }^{\text {relax }}-\mathrm{S}_{0}{ }^{\mathrm{FC} \mathrm{S1}}, \mathrm{T}_{1}{ }^{\text {relax }}-\mathrm{S}_{0}{ }^{\mathrm{FC}}{ }^{\mathrm{T} 1}$ emissions. 


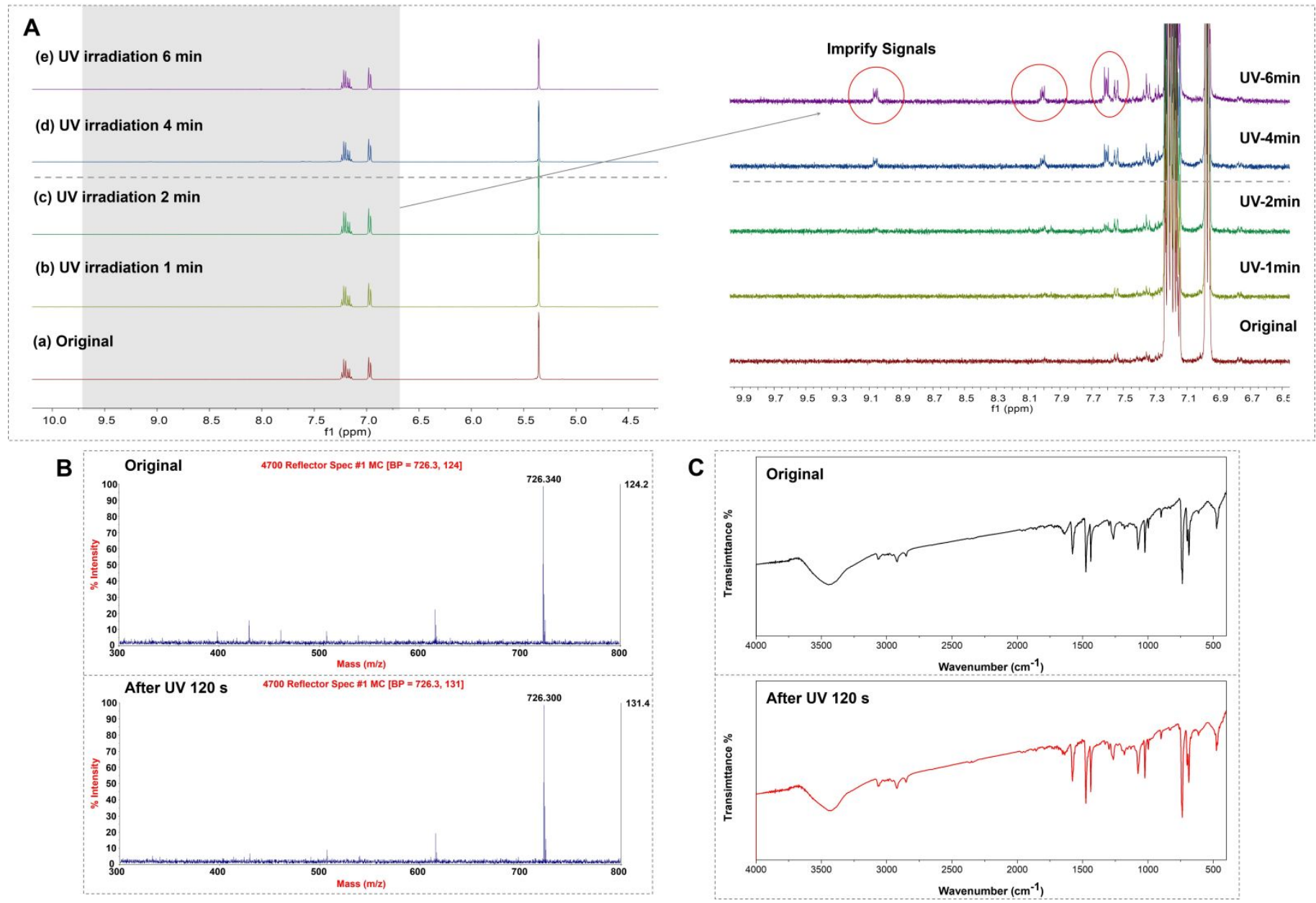

Figure S7. Fundamental characterizations of compound 1 before and after UV light irradiation. (A) The ${ }^{1} \mathrm{H}$ NMR spectra in $\mathrm{CD}_{2} \mathrm{Cl}_{2}$ upon irradiation within 0-6 min. (B) The MS (MOLDI-TOF) of compound 1 (10 $\left.\mu \mathrm{M}\right)$ before and after UV irradiation for $120 \mathrm{~s}$. (C) The FTIR spectra of compound $1(10 \mu \mathrm{M})$ before and after UV irradiation for $120 \mathrm{~s}$.
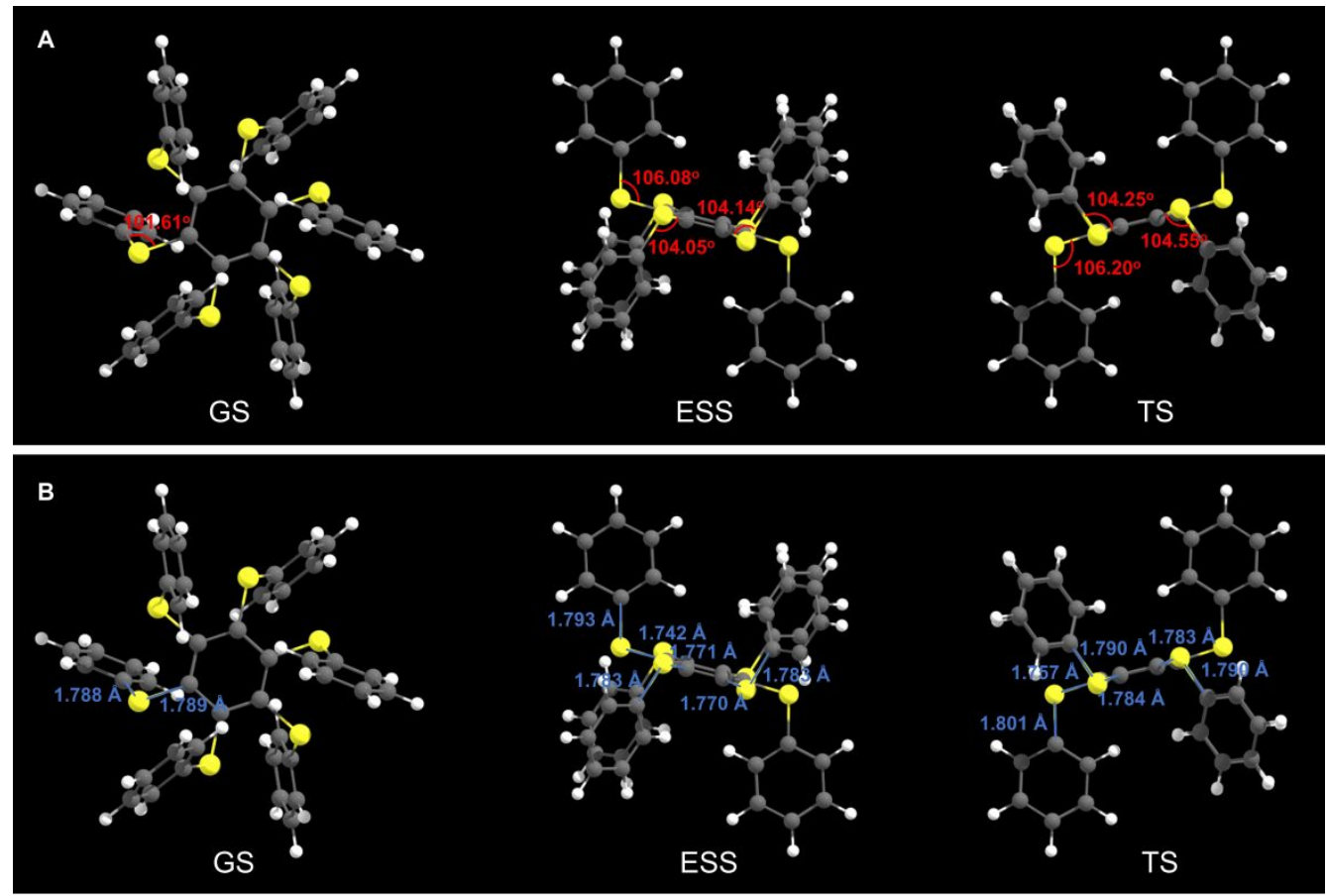

Figure S8. Conformation of compound 1: Ground State (GS), the Excited Singlet State (ESS) and Triplet State (TS): (A) Bond angles of C-S-C (red); (B) Bond distances of C-S (blue). 


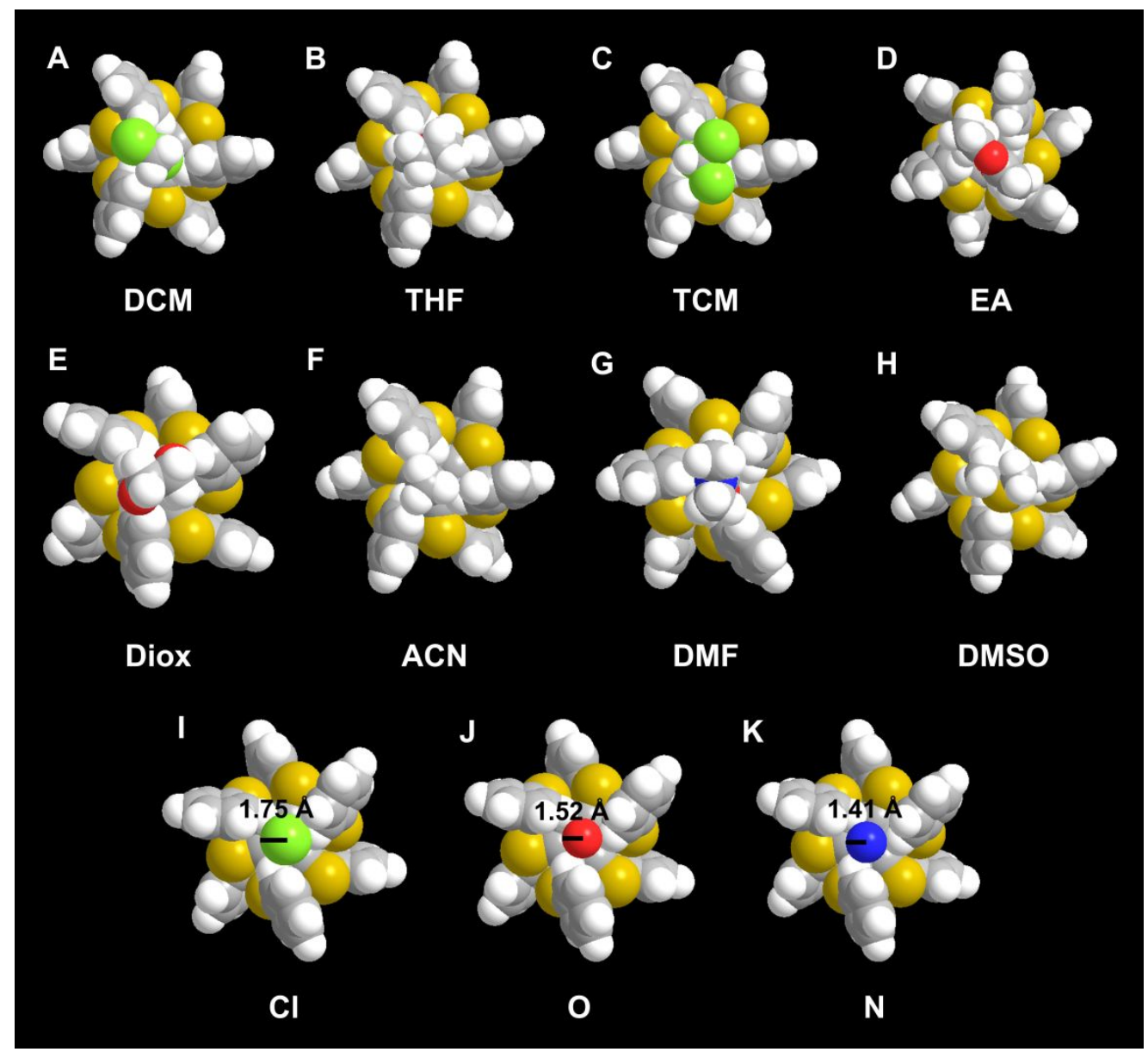

Figure S9. Equilibrium geometry of the GS and different solvent molecules (A-H). The geometric relationship between the chlorine atom (I), oxygen atom (J) and nitrogen atom (K) and GS (the van der Waals radius of these atoms was indicated). 


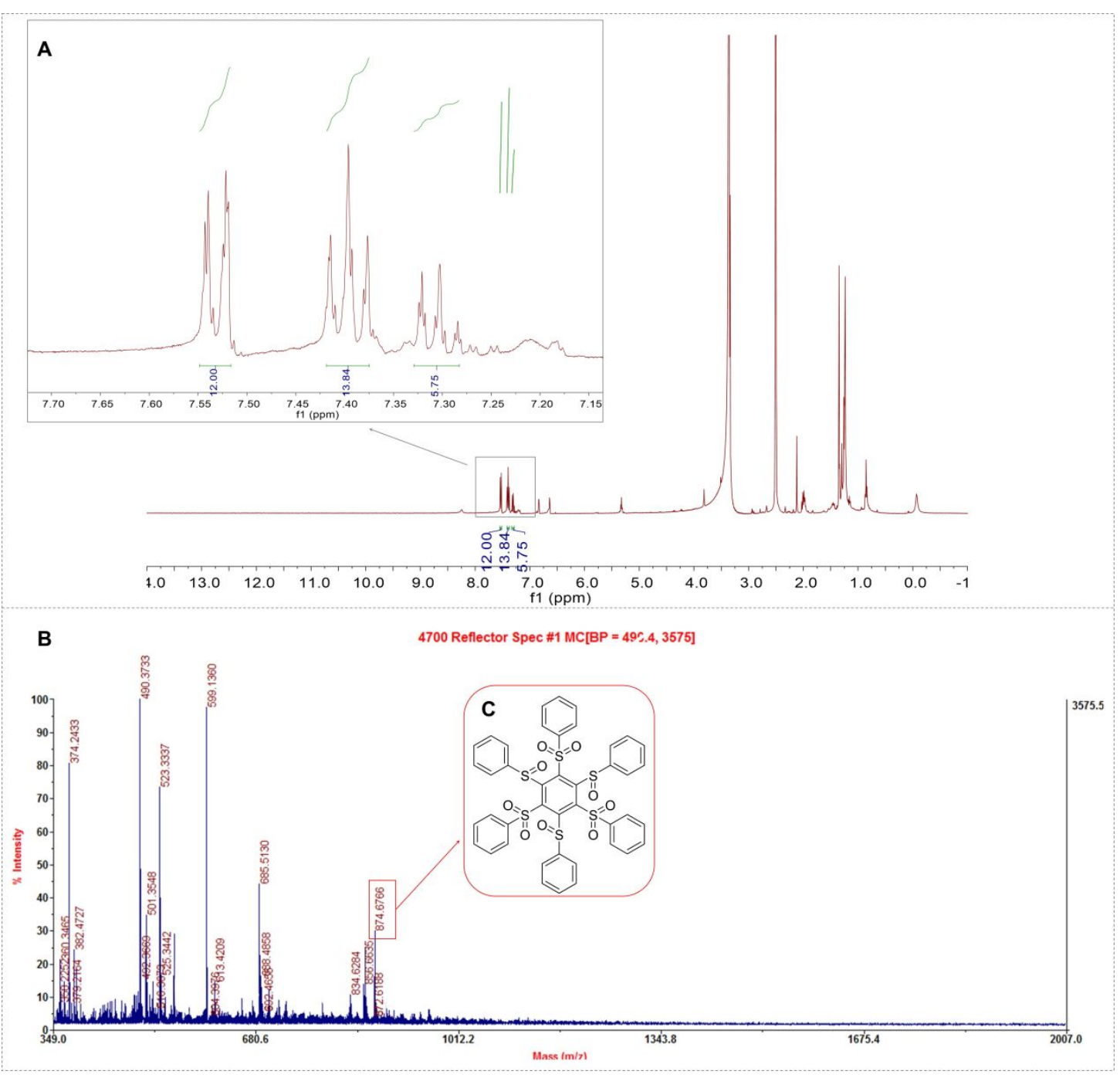

Figure S10. Fundamental characterization of the impurity orginated from UV light irridation of compound 1, including (A) ${ }^{1} \mathrm{H}$ NMR spectrum, (B) MS (MOLDI-TOF) and (C) the predicted molecular structure.
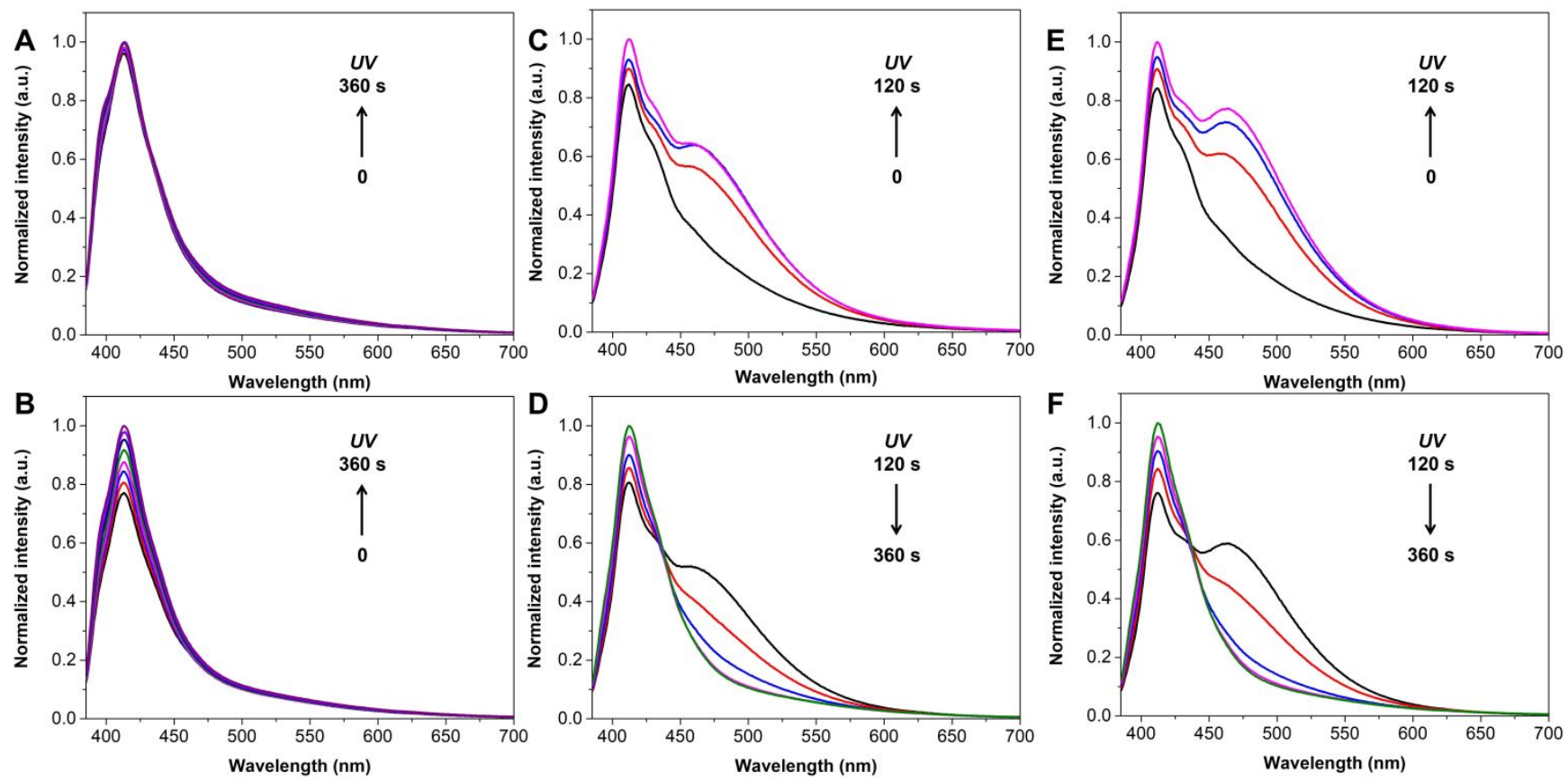

Figure S11. Emission spectral change of the impurities (A) and emission spectral change of the impurities mixed with compound 1 in the mass ratio of 1:1 (B), 1:4 (C, D), and 1:9 (E, F) under irradiation with UV lamp (365 nm, $5 \mathrm{~W})$ in DCM. 

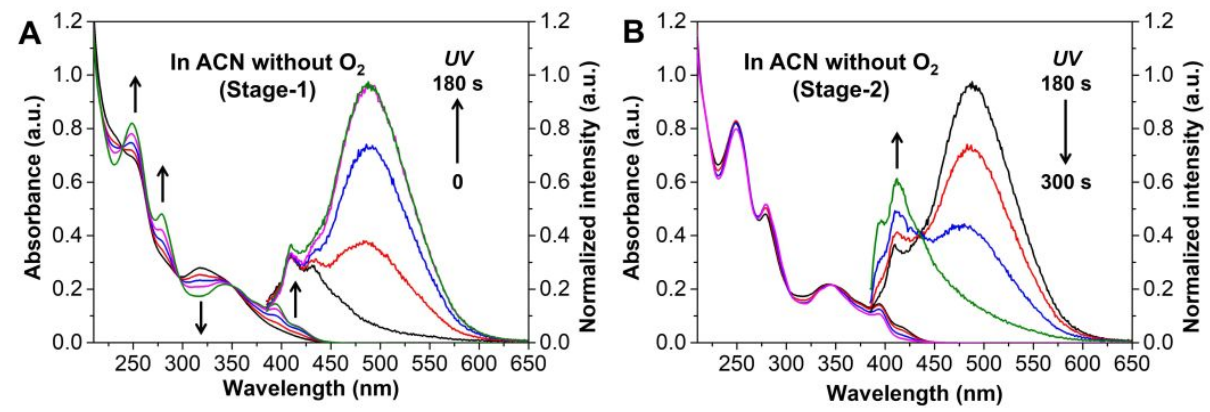

Figure S12. Absorption and emission spectral changes of compound 1 in degassed acetonitrile under irradiation with strong UV lamp (365 nm, 5W) for (A) 0-180 s and (B) 180-300 s under argon atmosphere.

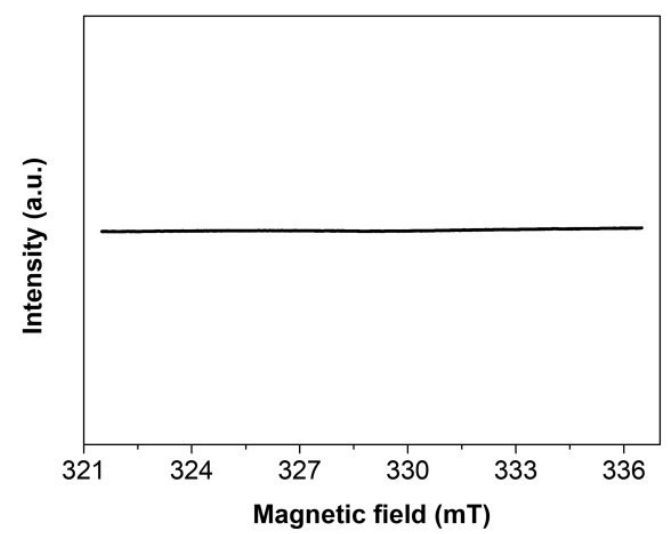

Figure S13. The ESR spectrum of compound $1(10 \mu \mathrm{M})$ in DCM after UV light irradiation for $120 \mathrm{~s}$.

\section{References.}

S1. Weng, T.; Baryshnikov, G.; Deng, C.; Li, X.; Wu, B.; Wu, H.; Ågren, H.; Zou, Q.; Zeng, T.; Zhu, L., A Fluorescence-Phosphorescence-Phosphorescence Triple-Channel Emission Strategy for Full-Color Luminescence. Small 2020, 16, 1906475. 